Gitro, C. M., and Coauthors, 2018: Using the multisensor advected layered precipitable water product in the operational forecast environment. J. Operational Meteor., 6 (6), 59-73, doi: https://doi.org/10.15191/nwajom.2018.0606

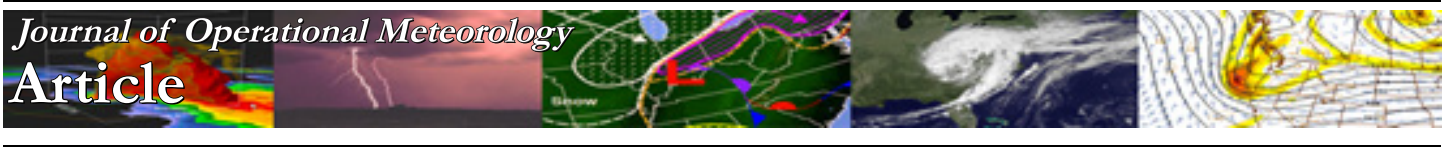

\title{
Using the Multisensor Advected Layered Precipitable Water Product in the Operational Forecast Environment
}

\author{
CHRISTOPHER M. GITRO \\ NOAA/NWS, Kansas City/Pleasant Hill, Missouri \\ MICHAEL L. JUREWICZ, SR. \\ NOAA/NWS, Binghamton, New York \\ SHELDON J. KUSSELSON \\ NOAA/NESDIS/OSPO/Satellite Product and Services Division, College Park, Maryland (Ret.) \\ JOHN M. FORSYTHE, STANLEY Q. KIDDER, EDWARD J. SZOKE, DANIEL BIKOS, and ANDREW S. JONES \\ Cooperative Institute for Research in the Atmosphere, Colorado State University, Fort Collins, Colorado \\ CHAD M. GRAVELLE \\ NOAA/NWS/Operations Proving Ground, Kansas City, Missouri, and Cooperative Institute of Mesoscale Meteorological Studies, \\ University of Oklahoma, Norman, Oklahoma \\ CHRISTOPHER GRASSOTTI \\ NOAA/NESDIS Center for Satellite Applications and Research and University of Maryland, ESSIC/CICS-MD, College Park, Maryland
}

(Manuscript received 18 December 2017; review completed 11 May 2018)

\begin{abstract}
The Cooperative Institute for Research in the Atmosphere, via the Joint Polar Satellite System Proving Ground, developed an advectively blended layered precipitable water (ALPW) product that portrays moisture profiles at a common time across the grid. Using water vapor profile retrievals from the National Oceanic and Atmospheric Administration's Microwave Integrated Retrieval System (MiRS) aboard polar-orbiting spacecraft, the ALPW product is able to depict the moisture distribution for four atmospheric layers. The ALPW layers are advected forward in time every 3-h using Global Forecast System model winds. Advective blending offers a reduction to the visual limitations seen with traditional non-advected layered precpitable water (LPW) imagery, as satellite swath lines and data discontinuities largely are removed. Having the same temporal resolution as LPW imagery, the new ALPW product offers a more continuous and complete picture of the moisture distribution in these four atmospheric layers (surface-850 hPa, 850-700 hPa, 700-500 hPa, and $500-300 \mathrm{hPa}$ ). The advected product also is easier for forecasters to interpret as the analysis at a common time and grid makes the ALPW product comparable to operational model guidance. This paper demonstrates the utility of the ALPW product as a situational awareness tool by highlighting the environments associated with three recent high-impact flash flood events. Initial findings indicate that ALPW data have improved the detection capability for tracking deep tropospheric moisture plumes from source regions well-removed from the flash flood locations.
\end{abstract}

\section{Introduction}

Flash flooding remains a significant contributor to weather-related fatalities across the United States each year. In 2015, 182 persons lost their lives to flash flooding, which was well above the 10-yr average of 82 fatalities annually (www.nws.noaa.gov/om/ hazstats.shtml). Recent high-profile events such as the (i) 2010 Albert Pike, Arkansas, campground case (20 fatalities; Holmes and Wagner 2011), (ii) 2013

Corresponding author address: Christopher M. Gitro, 1803 North 7 Highway, Pleasant Hill, MO 64080

E-mail: christopher.gitro@noaa.gov 
Oklahoma City tornado and flash flood event (13 fatalities; NWS 2014), (iii) 2015 Hildale, Utah, and Zion National Park tragedies (21 fatalities; R. Graham 2016, personal communication), and (iv) historic June 2016 West Virginia flood event (21 fatalities; Keighton et al. 2016) underscore the importance of anticipating meteorological patterns associated with extreme rainfall, and constitute a reminder of our nation's susceptibility to flash flooding.

Flash flood research using satellite observations received a heightened level of attention in the 1970s and 1980s following several high-impact flash flood events such as the Rapid City, South Dakota, flash flood of 1972 (Maddox et al. 1978), Big Thompson Flood of 1976 (Caracena et al. 1979), and Johnstown, Pennsylvania flash flood of 1977 (Bosart and Sanders 1981). Combined, these three events took the lives of hundreds, which emphasized a need for accurate prediction and detection of flash floods (Mogil et al. 1978). In the years immediately following these tragedies, several papers discussed using satellite-based infrared cloud properties (Scofield 1987; Vincente et al. 1998) and microwavebased quantitative precipitation estimation techniques (Ferraro 1997; Ferraro et al. 2000; Weng et al. 2003) to help better anticipate excessive rainfall and flash flooding. More recently, however, attention has been placed on atmospheric rivers [e.g., Newell et al. 1992; Cooperative Institute for Research in the Atmosphere (CIRA) 2016)] and how these elongated corridors of strong water vapor transport influence excessive rain and snowfall production across coastal and mountainous areas of the western United States (e.g., Zhu and Newell 1998; Neiman et al. 2002; Ralph et al. 2004; Dacre et al. 2015; Cordeira et al. 2017). Despite this recent interest, only limited discussion has occurred on the influence these atmospheric rivers have on heavy precipitation production outside of areas along the West Coast, especially for locations far removed from the original moisture source regions (Moore et al. 2012; Lavers and Villarini 2013; Nayak et al. 2016). In fact, Mahoney et al. (2016) briefly addressed geographical differences by discussing how southeastern United States heavy rain events often differ from traditional West Coast atmospheric river cases-noting how the former events may experience moisture advection from multiple source regions. A thorough literature review offers a fairly dated discussion (Maddox 1981; Funk 1986; McGuirk and Ulsh 1990; Thiao et al. 1995) on the utilization of Geostationary Operational Environmental Satellite (GOES) or Polar Operational Environmental
Satellite (POES) imagery for the recognition of favorable synoptic and/or mesoscale patterns for flash floods from a satellite pattern recognition viewpoint, especially for environments that fall outside of the distinctive and often well-detected atmospheric river patterns. This study attempts to show how POES data, in particular, can be used to highlight favorable moisture transport into a region prior to the onset of heavy precipitation.

In an effort to help forecasters anticipate moisture transport as a precursor to heavy precipitation development, CIRA developed the blended total precipitable water (TPW, commonly referred to as PWAT for atmospheric sounding analysis), percent of normal, and blended rain rate products (Kidder and Jones 2007; Forsythe et al. 2012, 2015) — where blended refers to a collection of disparate sensors used to create a map of a selected geophysical variable (water vapor in this case). These products have been created operationally at the National Oceanic and Atmospheric Administration's (NOAA) National Environmental Satellite, Data, and Information Service's (NESDIS) Office of Satellite and Product Operations (OSPO) since 2009 - using polarorbiting satellites - and are distributed throughout the National Weather Service (NWS) for operational use. While the blended TPW product depicts the full integrated moisture content from the Earth's surface to space, it fails to offer information on the vertical moisture distribution at predetermined levels in the atmosphere. In addition, the operational TPW product also has a tendency of being most sensitive to low-level moisture contributions (Forsythe et al. 2015; LeRoy et al. 2016), which could mask important moisture plumes at higher levels. This notwithstanding, the blended TPW product repeatedly has shown its operational utility leading up to, and during, high-impact hydrologic events (e.g., Moore et al. 2012; Cordeira et al. 2013; Gitro et al. 2014).

Recognizing that important details of atmospheric moisture content may be lost during the TPW blending process, while also leveraging NOAAsupported advances in water vapor profile retrievals, CIRA and the National Aeronautics and Space Administration (NASA) Short-term Prediction Research and Transition Center (SPoRT) developed a multisensory, non-advected, blended, and layered precipitable water product (LPW, Fig.1; Forsythe et al. 2015). In this product, LPW represents the depth of water in millimeters if all of the water vapor were condensed between two given pressure levels. LPW imagery allows forecasters to track water vapor flow at 


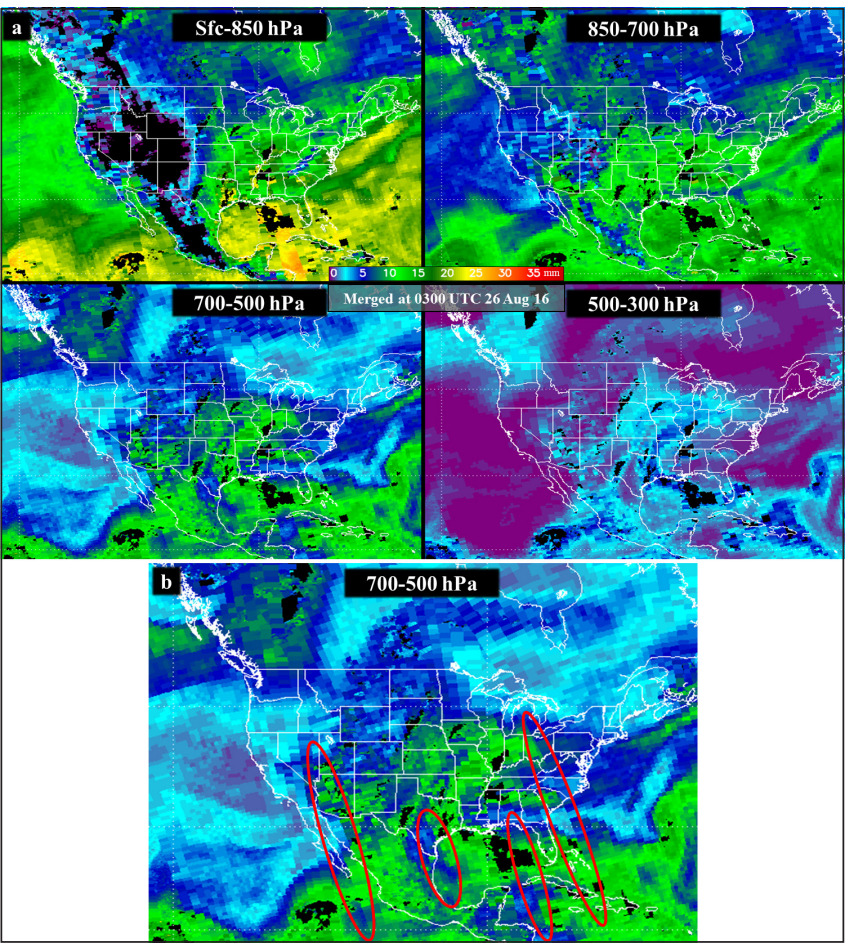

Figure 1. (a) Example of current LPW imagery valid 0300 UTC 27 August 2016 and (b) enlarged 700-500$\mathrm{hPa}$ panel with satellite swath lines outlined with red ovals. Blackened areas seen on all panels in regions of higher precipitable water $(\mathrm{mm})$ represent precipitation as microwave sounding retrievals fail in these areas. Large blackened area stretching from western Canada south through central Mexico in the surface-850$\mathrm{hPa}$ panel represents areas not calculated in response to moisture retrievals being below the surface. Click image for an external version; this applies to all figures and tables hereafter.

predetermined layers, thus improving the assessment of moisture transport and its availability for heavy precipitation events. Furthermore, it provides water vapor distribution information in cloudy regions, which serves as an improvement over traditional GOES water vapor imagery by allowing one to easily see the motion of water vapor through non-precipitating clouds. While LPW is not officially a NOAA operational product, it is distributed experimentally in near real-time to NWS National Centers and select Weather Forecast Offices (WFOs). The results of NWS feedback regarding the use and benefits of LPW imagery performed at WFOs on the West Coast, Alaska, and Puerto Rico are summarized by LeRoy et al. (2016). In that study, $>50 \%$ of forecasters ranked the LPW product as having a "large" impact to daily forecast preparation when used alone, or when compared to the blended TPW product. LPW is commonly referenced in Weather Prediction Center (WPC) mesoscale precipitation discussions for heavy rain and in National Hurricane Center (NHC) Atlantic tropical weather discussions when forecasters discuss the environment within and adjacent to tropical waves.

The purpose of this paper is to introduce the new advected LPW product (Fig. 2, hereafter referred to as ALPW; available online at cat.cira.colostate.edu/sport/ layered/advected/lpw.htm), as well as to highlight the added situational awareness that may be provided to forecasters by incorporating ALPW imagery into NWS forecast operations. Even though the ALPW product is similar to the LPW product, initial feedback from a small subset of NWS forecasters suggests that the improved visual quality and constant analysis time of the ALPW product likely will be better received by the operational community because satellite swath lines and other data discontinuities are mitigated in the ALPW blending process. The improvement in visual quality is apparent by comparing Figs.1 and 2. In Fig. 1, LPW represents the combination of water vapor measurements stitched together from observations at different times, whereas in

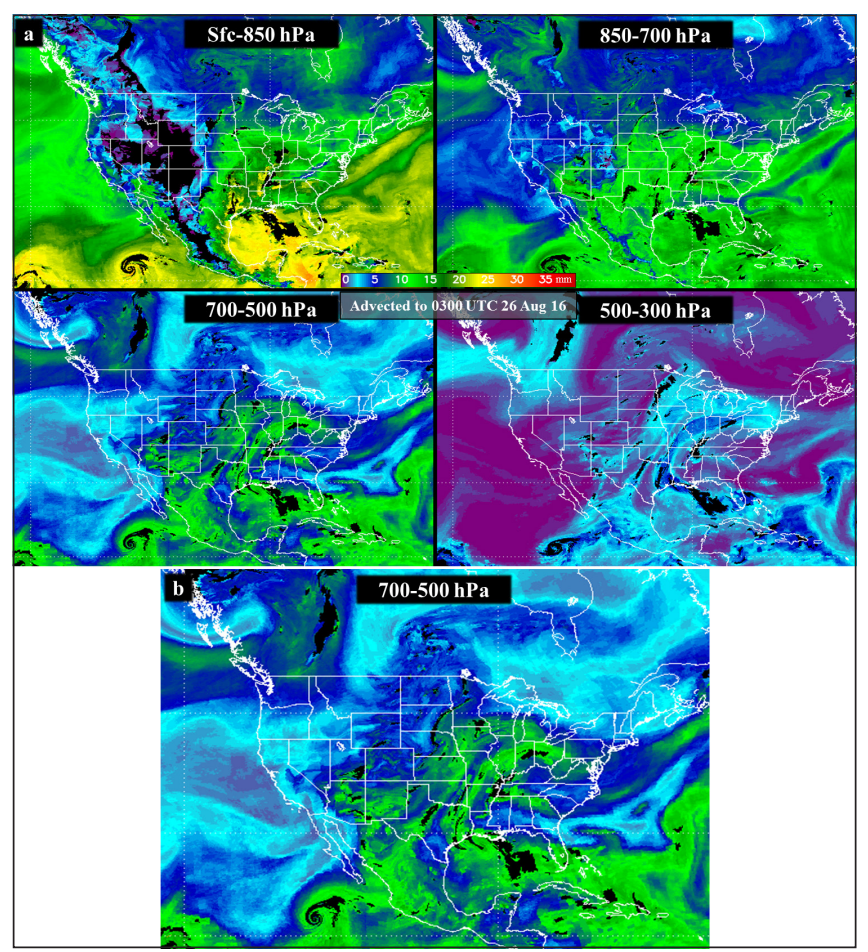

Figure 2. Same as Fig. 1 except for ALPW imagery. Notice the much smoother appearance of the data as many of the limitations seen with LPW imagery are reduced. 
Fig. 2, ALPW advects water vapor features using Global Forecast System (GFS) winds to provide a mapping of asynchronous observations to a common time. The result is a more cohesive and visually pleasing product that highlights the distribution of atmospheric moisture. Key improvements of ALPW over the blended TPW and LPW products will be highlighted further with a series of animations reserved for the 2016 West Virginia flash flood event in section $3 \mathrm{c}$.

As the paradigm of the NWS continues to shift towards a greater emphasis on centrally produced forecasts in order to achieve a common starting point and more horizontally consistent messaging (e.g., www. weather.gov/mdl $/ \mathrm{nbm}$ home), near real-time datasets will prove crucial at ensuring that situational awareness is maintained, particularly as the agency transitions to providing more impact-based decision support services. Because day-to-day mission requirements have increased in recent years, the time available for indepth meteorological analysis has decreased, which has led to the need for datasets that help condense missioncritical information for expedited interrogation. As a result, recognition of favorable patterns capable of extreme precipitation through the use of real-time remotely sensed products - such as CIRA's LPW products and GOES-R series satellite imagery-will be critical at ensuring the NWS meets its goal of building a weather-ready nation (www.weather.gov/news/130424roadmap) because early recognition of patterns will support the timely issuance of hazardous weather statements and escalation of decision-support activities. In the next section, a brief introduction of the new ALPW product is given, along with documentation of how this imagery differs from the LPW satellite product. In section 3, a series of recent case studies is shown using the new ALPW product to further highlight its versatility for increased situational awareness in the operational forecasting environment. Important signatures that forecasters may recognize prior to a heavy precipitation event will be shown, along with a discussion focused on product benefits over other traditionally used satellite datasets, such as GOES-R series water vapor channels and the blended TPW product. Finally, a conclusion is presented in section 4 .

\section{Data and Methods}

The construction of the LPW product and the new ALPW product used in this paper are now briefly discussed. More in-depth details of the LPW product are provided in Forsythe et al. (2015).

\section{a. Input satellite retrievals}

Profile retrievals obtained via the Microwave Integrated Retrieval System (MiRS, Boukabara et al. 2011) from five to seven polar orbiting spacecraft, depending upon availability, are used to create the LPW product. The satellites used for the cases considered in this paper are Suomi National Polar-orbiting Partnership (S-NPP), NOAA-18/19, MetOp-A/B, and Defense Meteorological Satellite Program F18. These spacecraft are all in a sun-synchronous orbit and sample at the same local time of day, 12-h apart. However, the orbital planes of the spacecraft are not equally spaced in time, which means there are periods of good temporal refresh and spatial coverage and periods of a few hours when no new data are available at a given location. This causes portions of the non-advected LPW product to remain unchanged when successive times are used in an animation because a new blended image is created every $3 \mathrm{~h}$, and lack of a new overpass means than older data are retained.

For the cases in this study, the MiRS version 7 retrieval algorithm was used on all sensors except the S-NPP, which employs the updated MiRS version 11 retrieval. Currently, the MiRS version 11 algorithm is operational on all sensors. Version 11 retrievals are at full sensor resolution, while those of version 7 are at the lower resolution of the advanced microwave sounding unit (AMSU)-A instrument. MiRS is a one-dimensional variational retrieval as described in Rodgers (2000). The primary source of water vapor profile information on these spacecraft is from a set of radiometer channels near the water vapor absorption line at $183 \mathrm{GHz}$. Unlike a radiosonde that reports at given levels, a layered context is the most logical approach to interpret satellite sounding products owing to the limited vertical information. Therefore, no more than four independent pieces of vertical moisture information are available from the MiRS retrievals. Unlike the GOES Legacy Atmospheric Profile product (www.goes-r. gov/products/baseline-legacy-vert-temp-profile.html), the MiRS moisture solution is independent of current model forecast inputs, which makes corresponding LPW and ALPW imagery attractive comparisons to numerical weather prediction output (Forsythe et al. 2015). MiRS profiles are archived at the National Centers for Environmental Information. 


\section{b. $L P W$ product construction}

The LPW product, similar to the operational blended TPW, is produced at CIRA on a 16-km resolution Mercator projection grid that covers the global tropics and midlatitudes from $71^{\circ} \mathrm{N}$ to $71^{\circ} \mathrm{S}$. The product is created every 3 -h for the cases examined in this paper. The LPW product is produced on four vertical pressure layers: surface to $850 \mathrm{hPa}, 850-700 \mathrm{hPa}, 700-500 \mathrm{hPa}$, and $500-300 \mathrm{hPa}$. Surface pressure is obtained from a static topography dataset equivalent to the MiRS retrievals, and if the pressure is $<850 \mathrm{hPa}$, the first layer is surface- $700 \mathrm{hPa}$. As LPW is derived from passive microwave radiances, accurate retrievals are possible in cloudy conditions, but not in precipitating conditions that are currently flagged as missing in the LPW and ALPW products showcased here.

The LPW product is produced at blend times of 00 , $03,06,09,12,15,18$, and 21 UTC. Time weighting is not applied and only the most recent satellite observation at each grid box is used. It is conceivable that the blended retrievals within a file may be $1-9-\mathrm{h}$ prior to the blend time, with the majority of the retrievals within 4-h of the blend time. Data $\geq 9$-h after the blend time are not used in the creation of the LPW product.

\section{c. Advective blending methods}

The LPW product that has been evaluated by NWS forecasters prior to this paper was a composite of the most recent satellite overpass at each grid point, which has several limitations for users. First, because of the delay in transmitting and processing polar orbiting satellite data, the gridded LPW product is always a few hours old before it can be examined by a forecaster. Second, non-physical artifacts in the data owing to the overlap between satellite swaths or time discontinuities are often apparent to the end user. Finally, the LPW product is composed of a patchwork quilt of overpass times that can make comparisons to corresponding model output fields difficult. In order to overcome these limitations, the ALPW product (version 1) was developed at CIRA under the Joint Polar Satellite System Proving Ground Risk Reduction Project. Advective blending, where model winds are used to move satellite retrieved moisture fields to a common time, was pioneered for the operational TPW product by Wimmers and Velden (2011). In the TPW advective blending, vertically weighted lower-tropospheric winds are used to advect the entire column of moisture. In the
ALPW product presented in this paper, each layer is independently advected by the layer wind.

A schematic of the advective blending process and the final result for a swath is shown in Fig. 3. In this example with S-NPP data, a 4-h long trajectory was required to achieve a solution for the target grid box shown near San Francisco. The steps to perform the advective blending for version 1 of the ALPW are described below (for each remapped polar orbiting satellite swath, for each grid box in the product, and for each layer).

1. A target time is chosen. This is the same time $(00,03, \ldots, 21$ UTC) for each map.

2. The $0.5^{\circ}$ grid spacing GFS model winds from one production run spanning 9-h before the target time are gathered. Different runs of the GFS are not mixed. GFS forecast intervals are $3 \mathrm{~h}$.

3. The winds for the given layer are chosen. In version 1 , a wind near the midpoint of the four LPW pressure layers (i.e., 900, 800, 600, and $400 \mathrm{hPa}$ ) is used. Other vertically weighted winds may be used in future versions.

4. The GFS winds at the current position are used to advect backwards along the trajectory, using a $15-\mathrm{min}$ time step. This process is illustrated in Fig. $3 \mathrm{a}$ and is shown at 1 -h intervals for legibility. GFS winds from the two bounding 3-h GFS outputs are linearly interpolated in space and time to drive the back trajectory calculation. The version 1 advection process does not employ any vertical motion or movement of water vapor between layers during the parcel trajectory. This process could be studied in future work.

5. At the new grid box, the time of the current trajectory is compared to the remapped MiRS data on the same grid. If the trajectory time is older than the MiRS data time, a solution is found, the output grid box is populated with the LPW value, and the iteration is stopped. If the MiRS data are missing, typically due to rainflagged retrievals, the missing values are used.

6. If the iteration reaches $>9$-h before the target time, no solution is found and the advection terminates with missing data.

This same advection process is performed for all of the polar orbiting swaths containing data within 9-h of 


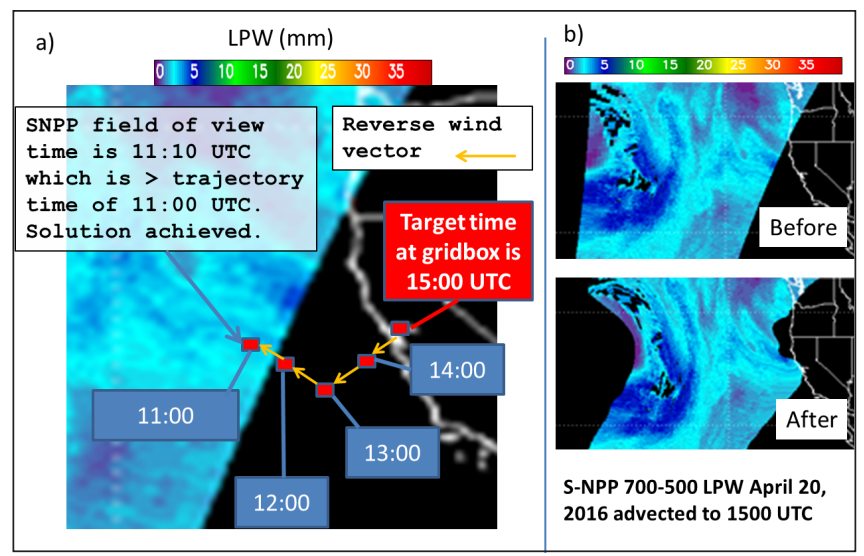

Figure 3. (a) Schematic of the advection process and (b) result of the advection process being applied to an S-NPP swath from 1500 UTC 20 April 2016. An example shown is from the 700 to 500 -hPa layer. In Fig. 3a the backtracking procedure continues until the trajectory time is less than the data time in the S-NPP swath.

the target time. Typically this is about $20-30$ overpasses of the 7 different spacecraft used in the ALPW product. For each spacecraft swath, a distorted (i.e., advected) swath is created as shown in Fig. 3b. To create the final version 1 ALPW product, all of the mapped swaths (excluding missing data) are averaged.

\section{d. $A L P W$ analysis}

For this paper, the ALPW product is analyzed 24- and 12-h prior to the start of heavy rainfall in the events discussed in section 3 . These times were chosen to emphasize how the ALPW product could be used in an operational environment to increase situational awareness before a heavy rain event commences. In addition to the 24- and 12-h times preceding heavy rainfall, 36-h animations also were created to illustrate the overall evolution of the ALPW imagery leading up to the events. For each case, observed soundings were created using the Universal Rawindsonde Observation Program version 6.2 (www.raob.com/) and inspected to quantify moisture advection signatures seen in the ALPW product. For this study, lifted parcels are those in the lowest $300 \mathrm{hPa}$ that produce the most unstable convective available potential energy (MUCAPE), calculated using the virtual temperature correction (Doswell and Rasmussen 1994). This method was applied to all soundings as it provides a better approximation of buoyancy for parcels in environments with elevated convection (Rochette et al. 1999; Moore et al. 2003).

This lifted parcel method will be used to highlight changes in warm cloud layer coalescence (Coal) depth (Davis 2004) on observed radiosondes for each event, which has been shown to be a reliable indicator of improved precipitation efficiency when depths are $>3-4 \mathrm{~km}(\sim 10000 \mathrm{ft})$ and raindrops are formed through the collision-coalescence process (Davis 2001). The primary purpose of this study is to test the following hypotheses: 1) ALPW techniques capture distinct plumes of water vapor in distinct layers that are key to analyzing regions of possible heavy rainfall; and 2) inference of the ALPW product at capturing the heavy rainfall threat is documented by radiosonde observations (RAOBs) showing an increased likelihood of heavy rainfall through upper-level moisture and Coal depths supporting efficient rainfall processes.

\section{Case study examples and discussion}

\section{a. September 2014: Northern Missouri heavy rain event}

On the evening of 9 September 2014, a severe weather event across northern Missouri rapidly evolved into a flash flood situation. By the conclusion of the event, $>228 \mathrm{~mm}$ ( 9 in, not shown) of rain fell across north-central Missouri as storms continuously developed and moved over the same area. Fortunately, no loss of life occurred, which may have been due to timely flash flood watch and warning statements leading up to and during the course of the event.

In the 24-h preceding the event start, ALPW data valid at 0300 UTC 9 September 2014 showed precipitable water values on the surface-850- and $850-700-\mathrm{hPa}$ layers between 10 and $15 \mathrm{~mm}(0.4$ and 0.6 in) across the Great Plains and Mississippi River Valley (Fig. 4). In the 700-500- and 500-300-hPa layers, and to a lesser extent in the lower layers, a wellestablished tropical moisture plume originated from off the Baja California coast from the remnant Hurricane Norbert circulation (Avila 2014). When the ALPW data are compared to the operational total blended TPW product, a distinct minimum in TPW is suggested across the Rocky Mountains (Fig. 5). This example highlights one of the strengths of the ALPW product. In the ALPW product, precipitable water contributions within the mid- and upper-tropospheric layers are readily apparent and suggest deep tropospheric moisture is present within these upper-level moisture plumes traced back to tropical source regions. The TPW 


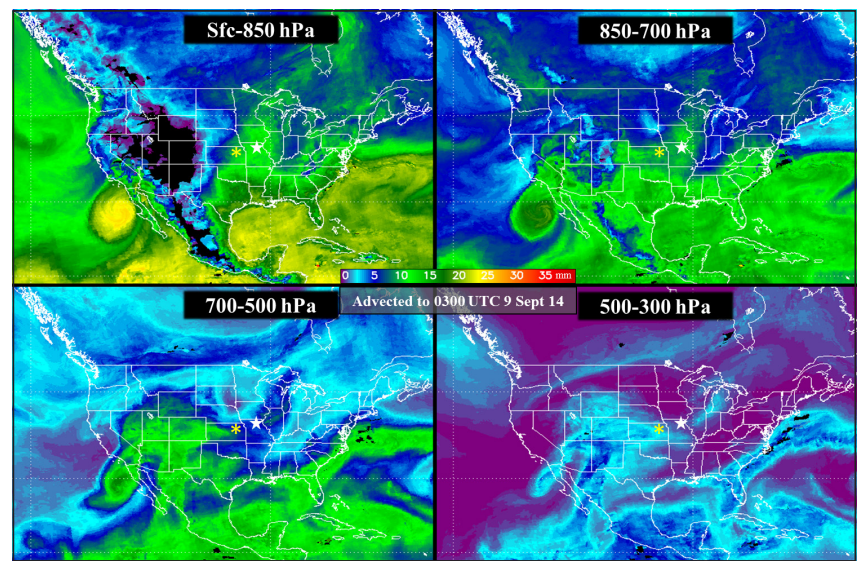

Figure 4. ALPW imagery valid 0300 UTC 9 September 2014. White stars represent the approximate location of the heaviest rainfall, with yellow asterisks representing the approximate location of TOP RAOB site.

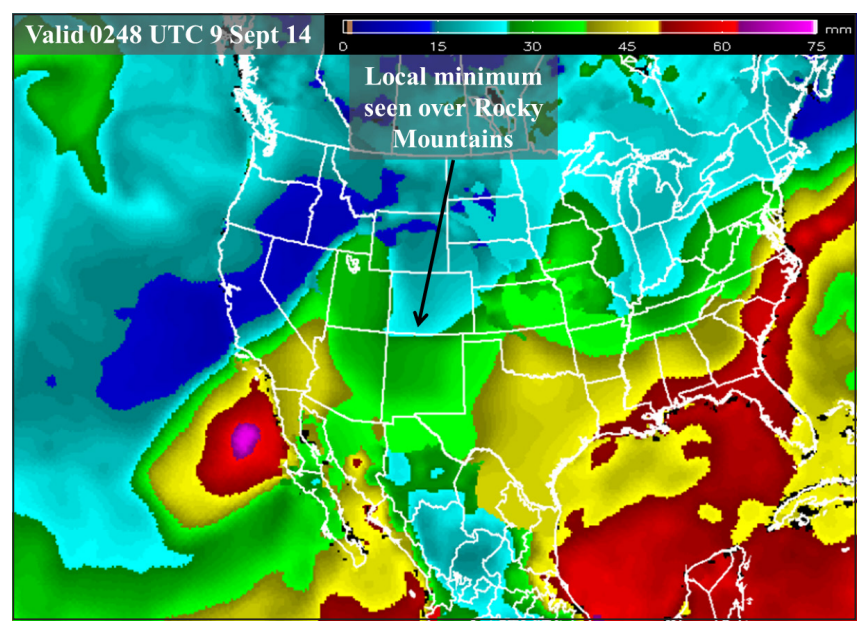

Figure 5. NOAA/NESDIS TPW imagery valid 0248 UTC 9 September 2014.

data fail to depict these mid- and upper-tropospheric moisture streams, likely due to the product being more sensitive to moisture contributions from lower levels of the atmosphere.

The importance of mid- and upper-tropospheric moisture contributions for heavy rainfall production has been thoroughly documented. Thiao et al. (1995) defined water vapor plumes (WVPs) as northward surges of well-defined boundaries of moisture from the intertropical convergence zone as viewed from GOES $6.7-\mu \mathrm{m}$ water vapor imagery. They stated how WVPs can, at times, become aligned with low- and midlevel equivalent potential temperature ridges that can be a precursor to heavy rainfall owing to high values of instability collocated with an abundantly moist air mass. In their period of study from 1989 to 1991, 129 warm-season heavy rain events were identified in which 24-h rainfall amounts were $>125 \mathrm{~mm}$ (5 in). Of the 129 events, 114 or $88 \%$ of the cases exhibited a well-defined WVP with $83 \%$ having tropical origins (17\% could be traced to subtropical or polar latitudes). In an attempt to define why mid- and upper-level moisture is important for heavy rainfall, Scofield et al. (2000) suggested that WVPs can lead to highly efficient rainfall environments because of cloud seeding of lower layers from above and promoting environments that limit the amount of dry air entrainment. The lack of dry air entrainment also was shown by Doswell et al. (1996) and Davis (2001) to be an important contributor for improved precipitation efficiency in heavy rain environments.

Following the methods described for determining Coal depth, the 3-4 km needed for dominant warm-rain production was surpassed on the 0000 UTC Topeka (TOP), Kansas, RAOB valid on 9 September 2014 with a depth of approximately $4.1 \mathrm{~km}$ (Fig 6). In addition, the TPW value of $36.83 \mathrm{~mm}$ (1.45 in) from the TOP RAOB fell within the 75-90th percentiles for this date (www.spc.noaa.gov/exper/soundingclimo/). Through 9 September, the ALPW data showed an eastward progression of a mid- and upper-level moisture plume, and by 1500 UTC 9 September, 12-h prior to the start of heavy rainfall, the 700-500- and 500-300-hPa layer moisture plume extended into northern Missouri (Fig. 7). Column moistening would then continue through

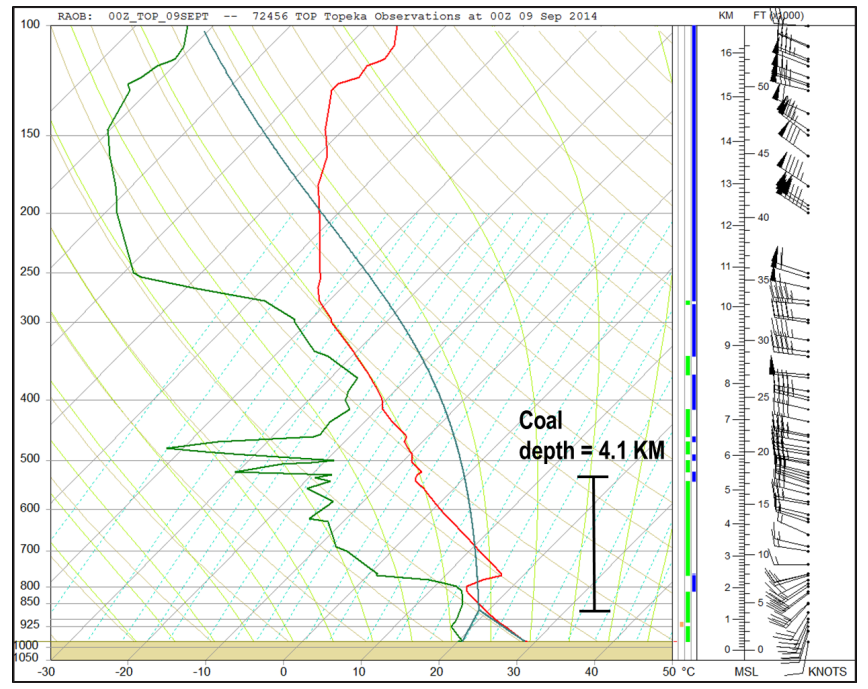

Figure 6. TOP RAOB valid 0000 UTC 9 September 2014. Red and green lines represent observed temperature and dewpoint respectively, with the MUCAPE parcel trace shown in cyan. Horizontal and vertical black bars represent the approximate warm cloud layer depth (Coal depth). 
the day as the 0000 UTC 10 September 2014 TOP RAOB indicated that the Coal depth increased to 4.5 $\mathrm{km}$ by evening with a corresponding TPW increase to $49.28 \mathrm{~mm}$ (1.94 in, Fig. 8), an all-time daily TPW maximum for this date (www.spc.noaa.gov/exper/ soundingclimo/).

This analysis illustrates how moisture contributions from very distant source regions can influence the environment conducive for heavy rainfall, and the importance of tracking these moisture plumes within the ALPW 700-500- and 500-300-hPa layers. ALPW panel PW traces show notable increases in these layers leading up to the period of heavy rainfall (Fig. 9). Because the presence of deep tropospheric moisture in the mid- and upper-levels has been shown to be important for increased precipitation efficiency by limiting dry air entrainment and supporting cloud seeding from above, along with further recognition that moisture advection in the low- and mid-levels is often most responsible for Coal depth changes (Fig. 8), this case illustrates how ALPW data can prove useful in increasing a forecaster's situational awareness of an evolving heavy rain threat, especially considering that the deep moisture plume was difficult to discern in the operational TPW product.

\section{b. September 2015: Colorado Plateau flash flood tragedy}

The deadliest weather event ever to impact the state of Utah occurred on 14 September 2015 when southern Utah and northern Arizona were impacted by slow-moving thunderstorms that moved over the flash flood-prone Colorado Plateau. By the end of the day on 14 September, 21 people had lost their lives in two separate areas across Utah, with an additional fatality occurring at a low-water crossing in northern Arizona. In the small town of Hildale, Utah, a van carrying 13 people trying to escape developing flood waters was struck from behind by a secondary flood wave. Further west, seven people lost their lives when flood waters quickly inundated the well-known slot canyons of Zion National Park. Despite well-placed and timely flash flood warnings by the Salt Lake City, Utah, and Las Vegas, Nevada, NWS WFOs, the loss of life resulting from this single event underscores the challenges posed by rapid flash flood development in remote communities and popular recreational areas (Graham et al. 2016).

Approximately 24-h before the flash flooding occurred, at 2100 UTC 13 September 2015, the ALPW

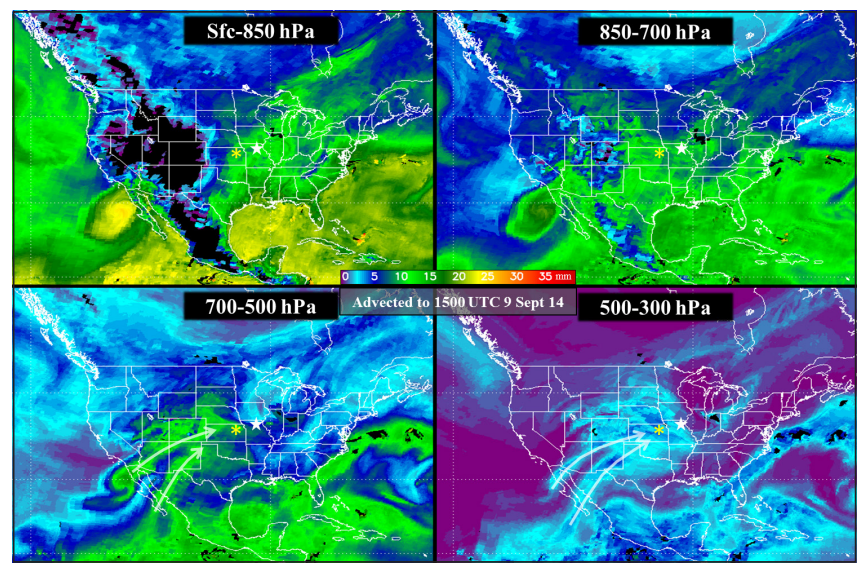

Figure 7. As in Fig. 4, but for ALPW imagery valid 1500 UTC 9 September 2014. White transparent arrows were added to the 700-500- and 500-300-hPa panels to highlight tracks of moisture plumes. Click image for a 36-h animation ending at 0300 UTC 10 September 2014, near the time of the first flash flood warning issuance.

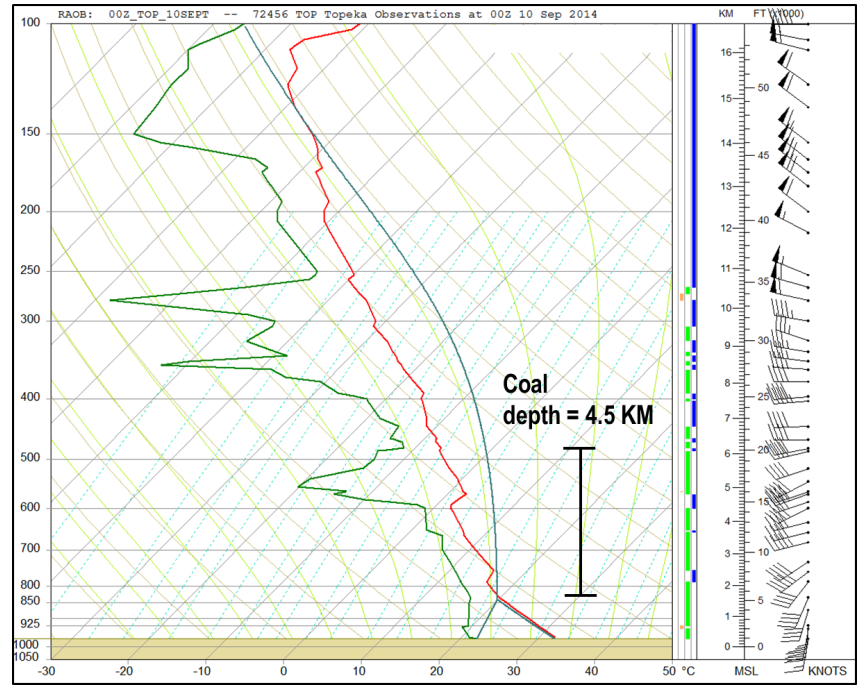

Figure 8. As in Fig. 6, but for the TOP RAOB valid 0000 UTC 10 September 2014.

data (Fig. 10) showed a deep tropospheric tropical moisture plume extending northward through western and central Arizona. Even the lowest layer (surface-850 $\mathrm{hPa}$, top left) highlighted a plume of higher precipitable water values over southwestern Arizona and southeastern California at this time. Subsequent analyses revealed that much of this moisture was associated with posttropical Hurricane Linda (Brown 2015). The 0000 UTC 14 September 2015 RAOB from Flagstaff (FGZ), Arizona, showed a shallow Coal depth of approximately $0.5 \mathrm{~km}$ (Fig. 11), which combined with ALPW imagery (Fig. 10) served to indicate the tropical moisture plume 


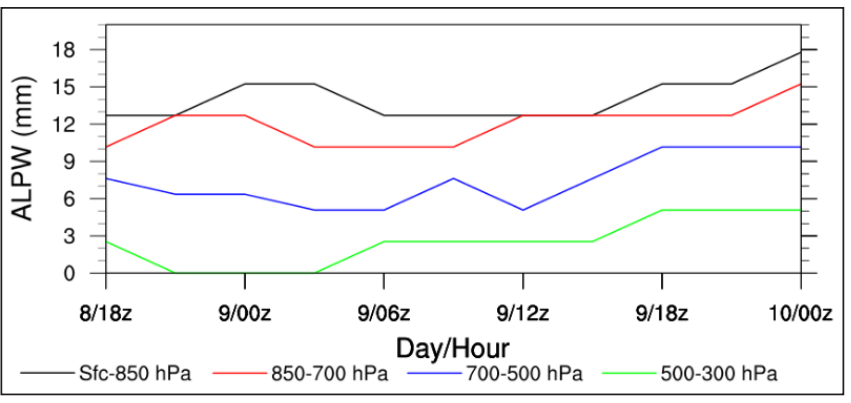

Figure 9. The $30-\mathrm{h}$ ALPW trace $(\mathrm{mm})$ ending at 0300 UTC 10 September 2014 for each layer taken near the white star depicted in Fig. 4.

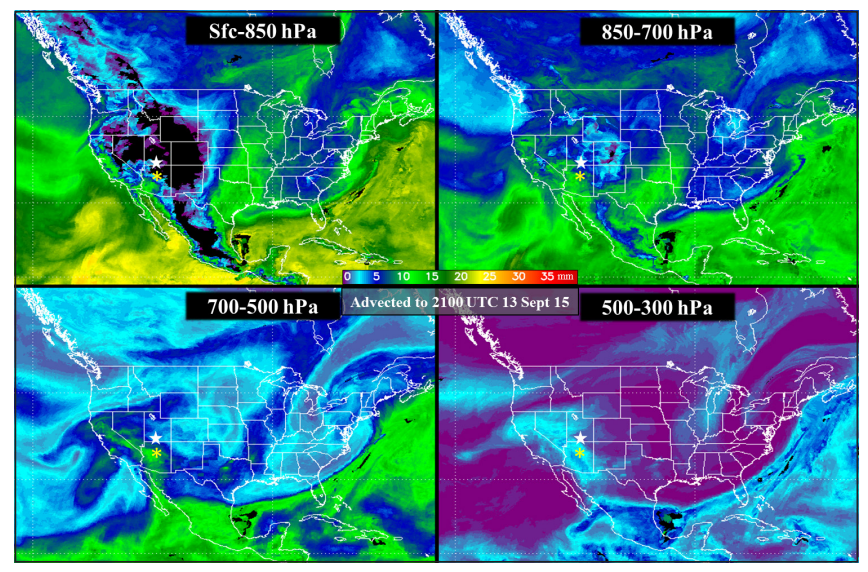

Figure 10. As in Fig. 4, but for ALPW imagery valid 2100 UTC 13 September 2015, with yellow asterisks representing the approximate location of the FGZ RAOB site.

was still to the south-southwest of FGZ. Twelve hours later at 0900 UTC 14 September 2015 (Fig. 12), ALPW data continued to show the presence of the deep eastPacific moisture plume, with the analysis indicating a slight shift eastward, which is most notable within the 700-500- and 500-300-hPa layers. The eastward shift likely occurred in response to increased steering layer flow in advance of a short-wave trough that had moved onshore in the Pacific Northwest (not shown). The 1200 UTC 14 September 2015 FGZ RAOB (Fig. 13) revealed the Coal depth had increased to $2.0 \mathrm{~km}$. While this value is less than the Coal depth usually associated with dominant warm-rain production and the environmental condition associated with excessive rainfall events (Davis 2004), there is little, if any, formal literature on Coal depths west of the Continental Divide. More importantly, the FGZ RAOB TPW value of 20.78 $\mathrm{mm}(0.82 \mathrm{in})$ fell just short of the upper 90th percentile (21.84 mm, $0.86 \mathrm{in}$ ) for 14 September values (www. spc.noaa.gov/exper/soundingclimo/). This suggests that

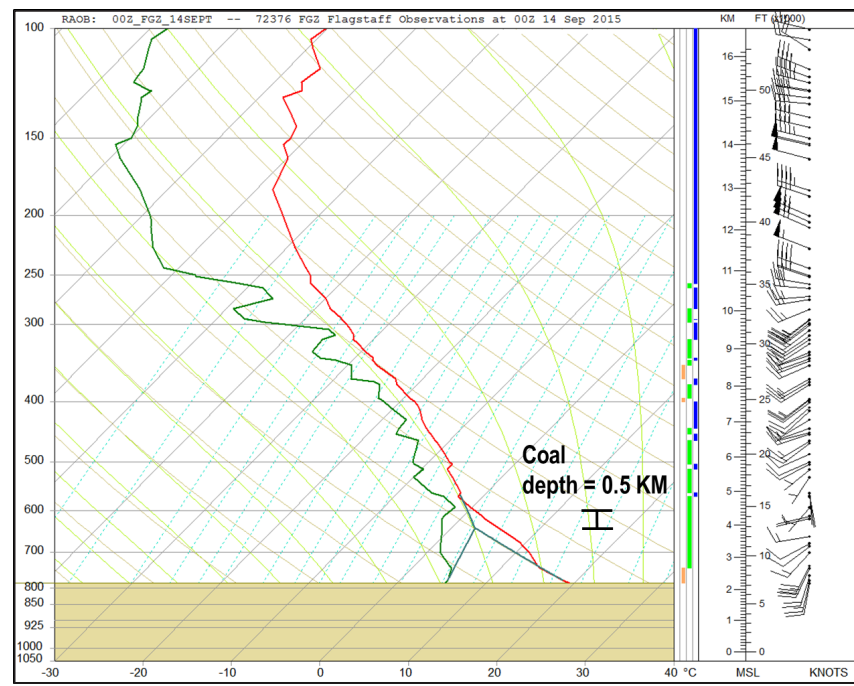

Figure 11. As in Fig. 6, but for the FGZ RAOB valid 0000 UTC 14 September 2015.

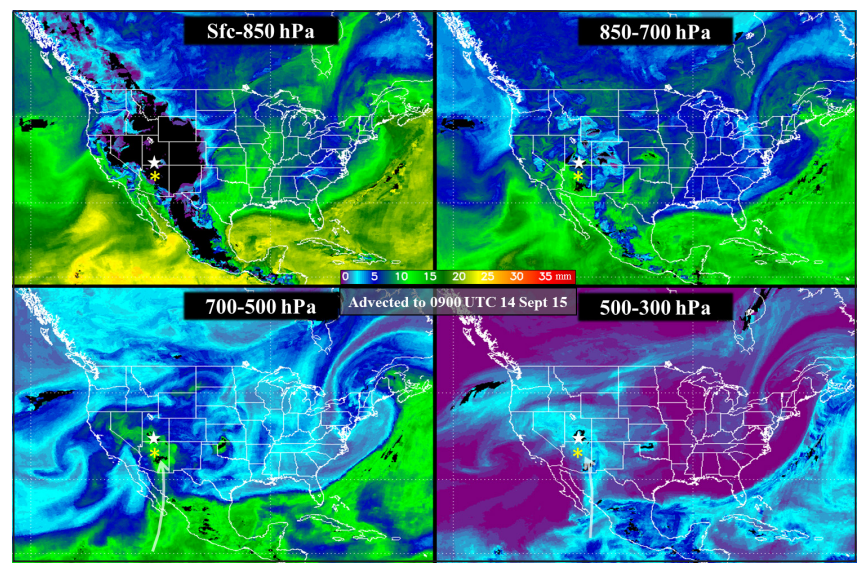

Figure 12. As in Fig. 10, but for ALPW imagery valid 0900 UTC 14 September 2015. White transparent arrows were added to the 700-500- and 500-300-hPa panels to highlight tracks of moisture plumes. Click image for a 36-h animation ending at 2100 UTC 14 September 2015.

the eastward shift of the deep moisture plume evident in ALPW data positively influenced the increase of the Coal depth at FGZ, which was most likely impacted by moisture increases in the 700-500-hPa layer (Fig. 14).

While it is recognized that timely flash flood warnings were issued, correspondence with local Salt Lake City, Utah, and Las Vegas, Nevada, NWS WFO management suggests that inspection of ALPW data prior to the event could have increased situational awareness of the impending flash flood threat ( $R$. Graham and S. Czyzyk 2017, personal communication). It is unclear if forecaster decision-making would have 
changed after analyzing the ALPW data in real-time; addressing such questions would need a formal ALPW forecaster evaluation that is beyond the scope of this paper. However, after inspection of the ALPW data, it is clear that the strength of the tropical moisture plume and upper-level moisture advection increased across the Colorado Plateau region of southern Utah in the hours leading up to the event.

\section{c. June 2016: West Virginia flash flood event}

On 22 and 23 June 2016, a historic flash flood occurred across West Virginia as deep-layered moisture interacted with a stalled frontal boundary. By the end of the event, 23 people lost their lives, which made this the single deadliest flash flood event in the United States since flash floods struck portions of Kentucky and Greater Nashville, middle Tennessee in May of 2010 (26 fatalities; NWS 2011; Moore et al. 2012). Torrential

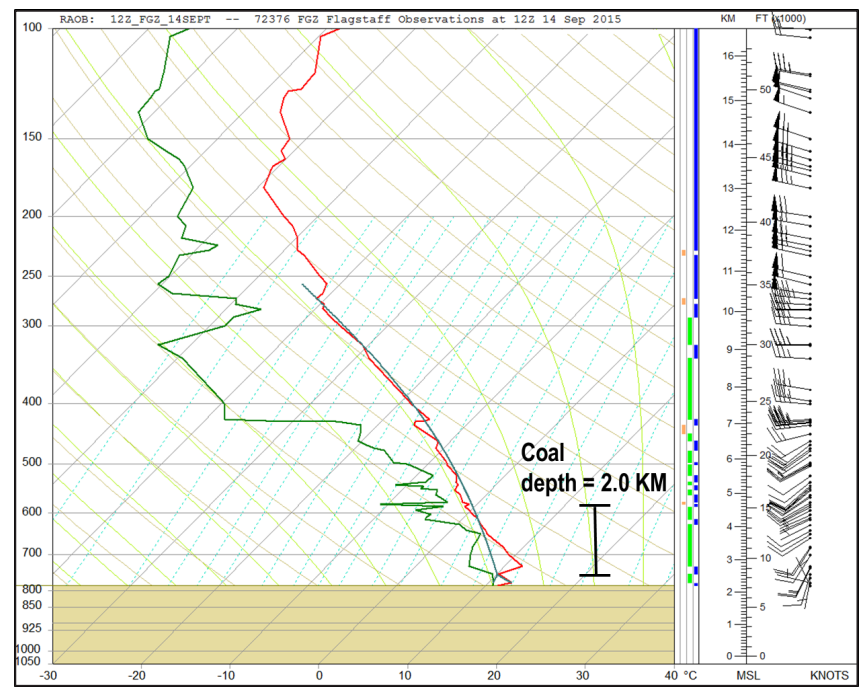

Figure 13. As in Fig. 6, but for the FGZ RAOB valid 1200 UTC 14 September 2015.

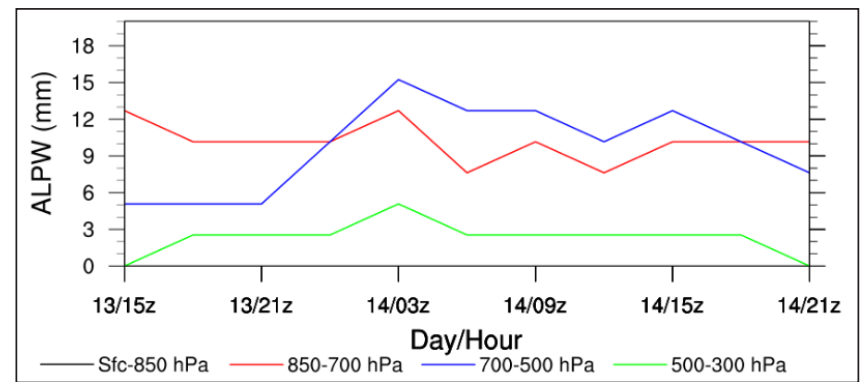

Figure 14. The 30-h ALPW trace (mm) ending at 2100 UTC 14 September 2015 for each layer taken near the white star depicted in Fig. 10. rains also were accompanied by severe weather, which required the issuance of 84 severe weather warnings for large hail, strong winds, and tornadoes by the Charleston, West Virginia, and Blacksburg, Virginia, NWS WFOs during the height of the event. Twentysix flash flood warnings also were issued, with three having flash flood emergency wording (NWS 10-922, see www.nws.noaa.gov/directives). Rainfall totals of 200-250 mm (8-10 in) were observed, with much of this occurring in $<12$-h between 0000 and 1200 UTC 23 June (Keighton et al. 2016).

Twenty-four hours before the event, ALPW data from all layers at 0600 UTC 22 June 2016 indicated that drier air had moved into central and northern West Virginia (Fig. 15) following the passage of a slowmoving cold front that was in the process of stalling across the region (not shown). The ALPW data indicated drier air was embedded in northwest flow aloft across Ohio and Indiana with all layers indicating deeper moisture and higher PW values further upstream across the upper Midwest and upper Mississippi River Valley. The 1200 UTC 22 June 2016 RAOB from Wilmington (ILN), Ohio, was consistent with the 0600 UTC ALPW imagery as dry air and steep midlevel lapse rates were observed in the 700-550-hPa layer (Fig. 16). The ILN RAOB also revealed a relatively shallow Coal depth of approximately $2.1 \mathrm{~km}$. Twelve hours later at 1800 UTC, ALPW data indicated that the higher PW values upstream over the northern plains and upper Mississippi Valley advected across Ohio and West Virginia (Fig. 17). Precipitation was occurring in this area, noted by missing MiRS retrievals (i.e., black areas around Indiana, Ohio, and West Virginia in Fig. 17). This notwithstanding, the data-void areas are embedded within high moisture content in all layers of the ALPW data. The 0000 UTC 23 June 2016 ILN RAOB (Fig. 18) indicated that the Coal depth had increased from 2.1 to $3.9 \mathrm{~km}$ in the $12-\mathrm{h}$ period, which is more than supportive for the warm-rain collision-coalescence precipitation production process; low-level moisture advection was most responsible for the increase in Coal depth (Fig. 19).

From a situational awareness perspective, this event is impressive because the ALPW data showed that a plume of tropical moisture extended into the central Appalachians from an eastern Pacific source region. This moisture plume is most noticeable in the 500-300hPa panel (Fig. 17) where upper-level moisture from two regions of the eastern Pacific - one off the coast of California and the other west of Mexico- converged 


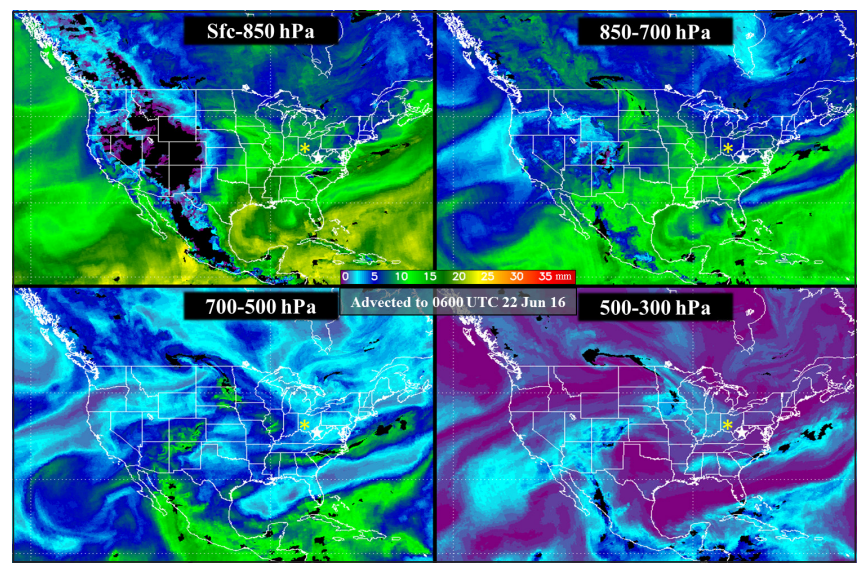

Figure 15. As in Fig. 4, but for ALPW imagery valid 0600 UTC 22 June 2016, with yellow asterisks representing the approximate location of the ILN RAOB site.

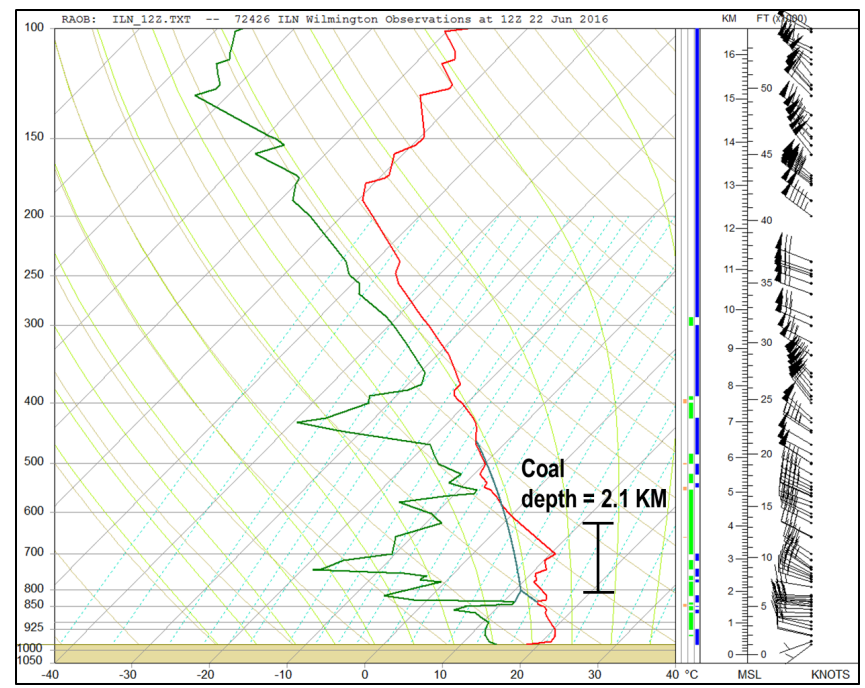

Figure 16. As in Fig. 6, but for the ILN RAOB valid 1200 UTC 22 June 2016.

over the central Rockies before continuing downstream into the central Appalachians along the northern periphery of an upper-level ridge. The moisture plume source region was well beyond $2000 \mathrm{~km}$ from the central Appalachians, and underscores how and why the ALPW data should be used by the operational forecasting community. Because these tropical moisture plumes are associated with deep tropospheric moisture, operational experience by the authors suggests these long-tracked signals are most noticeable on the 700-500- and 500300-hPa layers.

Similar to the events shown previously, the strength of the ALPW product over LPW and TPW data is for the forecaster to visualize a more cohesive and complete

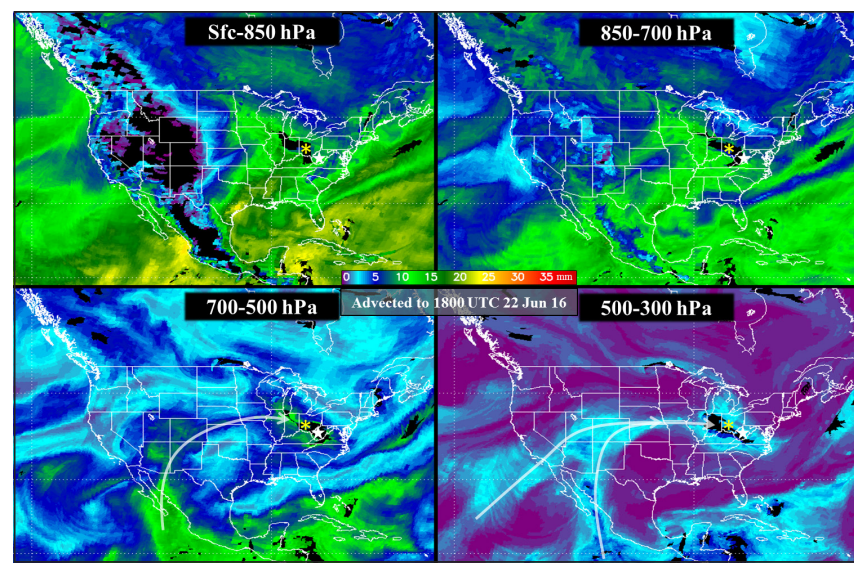

Figure 17. As in Fig. 15, but for ALPW imagery valid 1800 UTC 22 June 2016. White transparent arrows were added to the 700-500- and 500-300-hPa panels to highlight tracks of moisture plumes. Click image for a 36-h animation ending at 0600 UTC 23 June 2016.

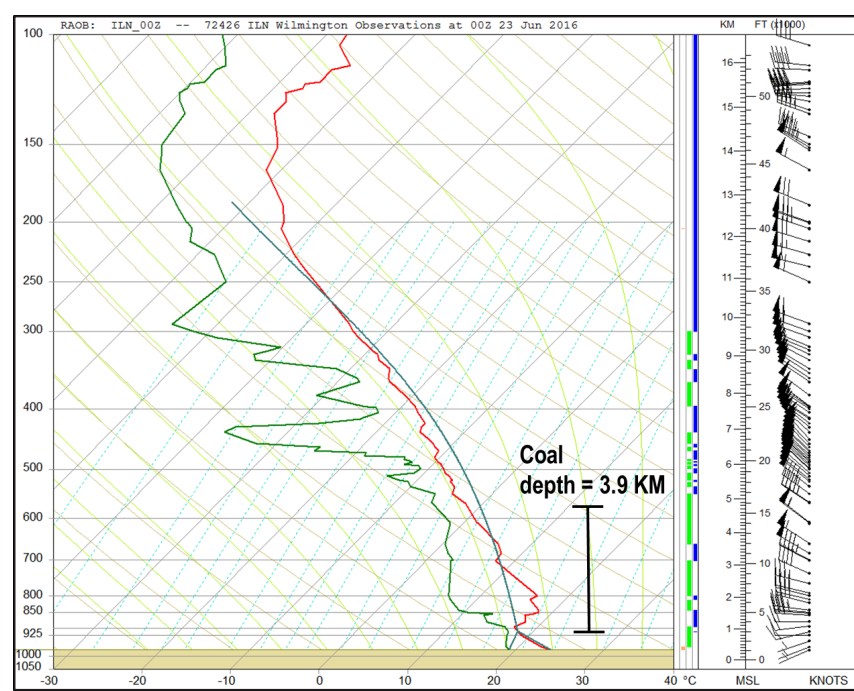

Figure 18. As in Fig. 6, but for the ILN RAOB valid 0000 UTC 23 June 2016.

picture of the mid- and upper-level PW profiles. When viewed in comparison to LPW imagery (Fig. 20), the ALPW's strength over LPW imagery is readily apparent as data discontinuities and satellite swath lines largely are removed. Furthermore, the advection of moisture from mid- and upper-levels depicted in animated ALPW imagery (Fig. 17) identifies the moisture plumes more readily than the animated TPW imagery (Fig. 21). This further illustrates how the ALPW imagery can better discriminate moisture layers in the vertical as they advect forward in time; moisture at different levels can be visualized more efficiently when compared to plan view TPW animations. When used together in 


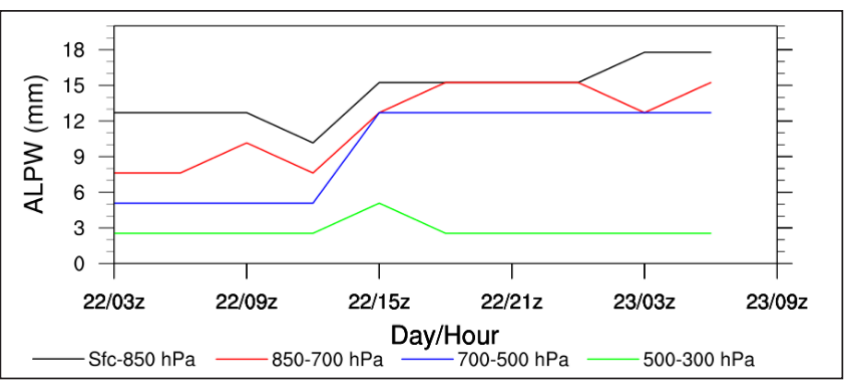

Figure 19. The 27-h ALPW trace (mm) ending at 0600 UTC 23 June 2016 for each layer taken near the yellow asterisk (ILN RAOB site) depicted in Fig. 15.

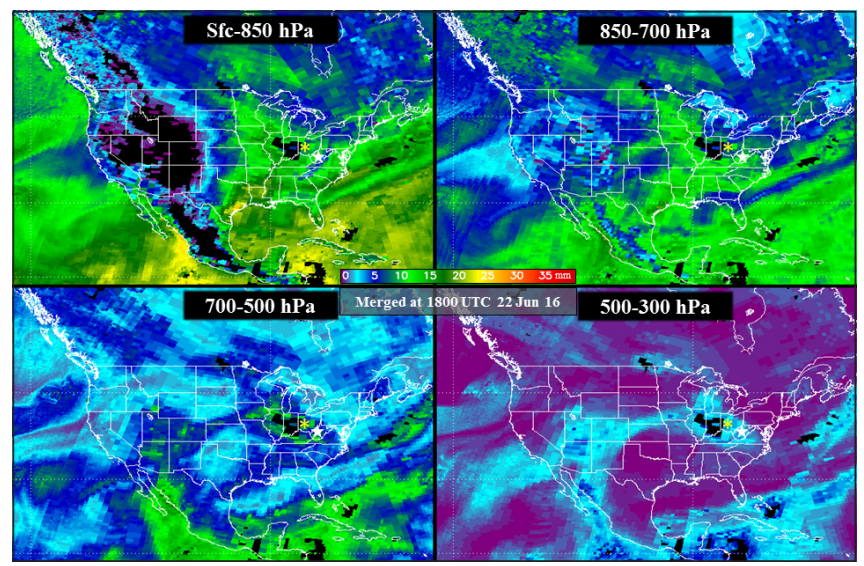

Figure 20. As in Fig. 1a, but for LPW imagery valid 1800 UTC 22 June 2016. Click image for a 36-h animation ending at 0600 UTC 23 June 2016.

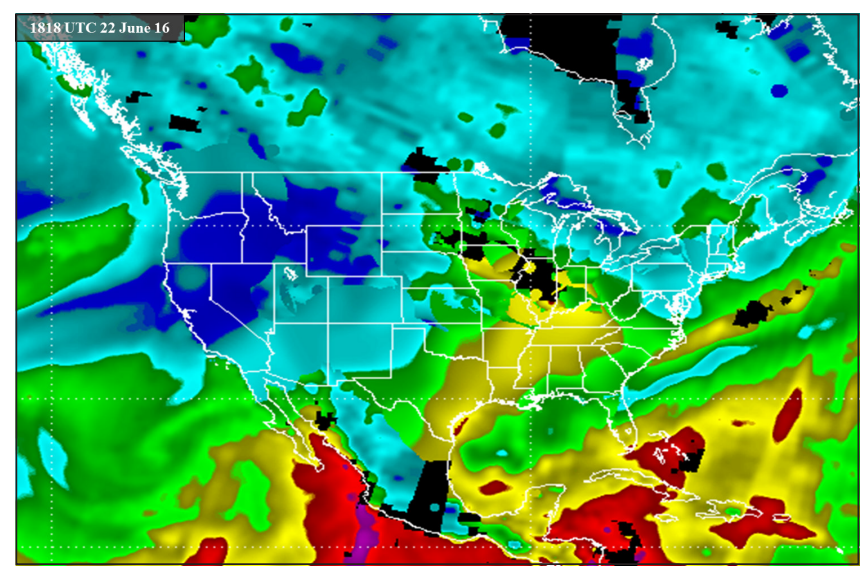

Figure 21. As in Fig. 5, but for TPW imagery valid 1818 UTC 22 June 2016. Click image for a 36-h animation ending around 0600 UTC 23 June 2016.

tandem, these two products allow for early recognition of signals that can serve as a catalyst for increased decision-support activities.

\section{Conclusions}

This paper highlights the ALPW's ability to assist forecasters with identifying moisture plumes, especially at 500-hPa and above, that often are associated with an environment conducive to heavy rainfall. The ALPW data are created through MiRS profile retrievals from seven polar-orbiting spacecraft and GFS model winds to horizontally advect remapped satellite swaths forward to a constant time. The remapped swaths are composited with equal weighting in the version 1.0 ALPW product used in this paper. This results in a smoother appearance when the ALPW product is compared to legacy LPW. In addition, LPW product limitations such as swath discontinuities, static satellite swaths, and non-uniform time in the scene mostly are removed during the ALPW advection process. The end result is a much clearer and more continuous product that early reviews from forecasters suggest is much easier to interpret in the operational forecast environment.

As highlighted in section 1, recent literature has identified the atmospheric river as a recognizable satellite signal that is associated with heavy rainfall. However, some satellite datasets, such as the operational NOAA/NESDIS blended TPW product, fail to partition the river or other moisture sources into discrete layers/ levels, especially in regions where low-level moisture is high. Recognizing that the blended TPW product is most sensitive to low-level moisture contributions, the ALPW product is offered as an additional tool for monitoring and tracking extensive mid- and upper-level moisture streams over a hemispheric scale.

From an operational forecasting perspective, the APLW product's ability to track individual moisture plumes prior to the onset of heavy precipitation can prove critical in anticipating high-impact hydrologic events. These deep tropospheric tropical moisture plumes supportive of a favorable environment for flash flood events were shown for three cases: Missouri in September 2014, the Colorado Plateau in September 2015, and West Virginia in June 2016. An analysis of the ALPW data from these cases revealed that the moisture plumes could be followed back to tropical source regions, in one instance $>2000 \mathrm{~km}$ away in the eastern Pacific.

Operationally, one of the most interesting aspects of the ALPW data is being able to infer an increased likelihood for heavy rain potential; moisture plumes as seen on the upper-level ALPW panels serve as an identifiable source for tropical moisture connections, 
while moisture profiles on lower-level panels serve as a signal for possible abrupt increases in Coal depths. Inferring a deepening Coal depth — with knowledge that a well-established tropical moisture feed exists further aloft - can undoubtedly serve to heighten forecaster situational awareness that an environment supportive of warm-rain production and high precipitation efficiency could become present (Doswell et al. 1996). In the western United States, increases in Coal depth may be best inferred from the 850-700-hPa panel (depending upon elevation), while the surface-850-hPa panel likely is best suited for areas east of the Continental Divide.

When used to augment existing TPW imagery, ALPW data give the forecaster a clearer picture of the evolving multi-layered moisture distribution. Recognizing that flash flooding leads to nearly 100 lives lost annually in the United States, advanced recognition of developing moisture plumes associated with an environment responsible for heavy rainfall production is critical as the NWS attempts to build a weatherready nation. To date, the ALPW product produced at CIRA is being distributed to the NWS WPC, NHC, and select WFOs for evaluation. NASA SPoRT provides a portion of this distribution and reformatting to make the data available for use by NWS software. The ALPW product is not currently operational in the NWS, but CIRA can add WFO's to the experimental distribution, if requested.

In addition to anticipating hydrometeorological events, ALPW imagery has the potential to increase situational awareness for operational forecasters in advance of other high-impact events, such as severe warm-season convection and winter storms. In the case of severe convection, the presence of elevated mixed layers (EMLs) (Carlson and Farrell 1983; Carlson et al. 1983) has been tied to the onset of a number of historic severe weather episodes (Farrell and Carlson 1989; Banacos and Ekster 2010). Tracking well defined dry punches in either the 850-700- and/or 700-500$\mathrm{hPa}$ layers of ALPW imagery, along with other satellite analysis techniques, could be used to help identify the approach of an EML. As for winter weather, the incorporation of midlevel moisture streams from the western Atlantic (readily observed in the $700-500-\mathrm{hPa}$ panels of ALPW imagery) has been shown to enhance snowfall potential for lake-effect snow bands in the eastern Great Lakes region (Jurewicz 2018). One area of future work could be the development of seasonal normal values. This would then allow forecasters the opportunity to compare real-time ALPW values to a seasonal climatology to help establish the rarity of a detected moisture plume. Similar work already has been completed for blended TPW data, with percent of normal data now readily accessible to forecasters.

Acknowledgments: The authors thank Randy Graham (former Meteorologist-In-Charge, NWS Salt Lake City, Utah) and Stanley Czyzyk (Science Operations Officer, NWS Las Vegas, Nevada) for their very helpful discussion on the benefits that ALPW data would have provided in advance of the southern Colorado Plateau flash flood tragedy of September 2015. Great appreciation also is extended to Kevin Fuell, Frank LaFontaine, Kevin McGrath, and Anita LeRoy of NASA SPoRT for their assistance in distributing the ALPW product, and to Natalie Tourville (CIRA, Colorado State University) for her assistance in obtaining numerous input datasets from NOAA. Additional appreciation is offered to Jeffrey Manion of NWS Central Region Headquarters for his initial review of the manuscript. Last, the authors thank three anonymous reviewers whose comments greatly improved the overall quality of the manuscript.

\section{REFERENCES}

Avila, L. A., 2014: National Hurricane Center tropical cyclone report: Hurricane Norbert. NOAA/NHC Rep. EP142014, 18 pp. [Available online at www.nhc.noaa. gov/data/tcr/EP142014 Norbert.pdf.]

Banacos, P. C., and M. L. Ekster, 2010: The association of the elevated mixed layer with significant severe weather events in the northeastern United States. Wea. Forecasting, 25, 1082-1102, Crossref.

Bosart, L. F., and F. Sanders, 1981: The Johnstown flood of July 1977: A long-lived convective system. J. Atmos. Sci., 38, 1616-1642, Crossref.

Boukabara, S.-A., and Coauthors, 2011: MiRS: An allweather IDVAR satellite data assimilation and retrieval system. IEEE Trans. Geosci. Remote Sens., 49, 32493272 , Crossref.

Brown, D. P., 2015: National Hurricane Center tropical cyclone report: Hurricane Linda. NOAA/NHC Rep. EP152015, 16 pp. [Available online at www.nhc.noaa. gov/data/tcr/EP152015_Linda.pdf.]

Caracena, F., R. A. Maddox, L. R. Hoxit, and C. F. Chappell, 1979: Mesoanalysis of the Big Thompson storm. Mon. Wea. Rev., 107, 1-17, Crossref. 
Carlson, T. N., and R. J. Farrell, 1983: The lid strength index as an aid in predicating severe local storms. Natl. Wea. Dig., 8 (2), 27-39. [Available online at nwafiles.nwas. org/digest/papers/1983/Vo108No2/1983v008no02Carlson-Farrell.pdf.]

, S. G. Benjamin, G. S. Forbes, and Y.-F. Li, 1983: Elevated mixed layers in the regional severe storm environment: Conceptual model and case studies. Mon Wea. Rev., 111, 1453-1473, Crossref.

CIRA, 2016: GOES-R atmospheric rivers. Accessed 1 November 2016. [Available online at rammb.cira. colostate.edu/training/visit/training_sessions/goes $\mathrm{r}$ atmospheric rivers/.]

Cordeira, J. M., F. M. Ralph, and B. J. Moore, 2013: The development and evolution of two atmospheric rivers in proximity to western North Pacific tropical cyclones in October 2010. Mon. Wea. Rev., 141, 4234-4255, Crossref.

, F. M. Ralph, A. Martin, N. Gaggini, J. R. Spackman, P. J. Neiman, J. J. Rutz, and R. Pierce, 2017: Forecasting atmospheric rivers during CalWater 2015. Bull. Amer. Meteor. Soc., 98, 449-459, Crossref.

Dacre, H. F., P. A. Clark, O. Martinez-Alvarado, M. A. Stringer, and D. A. Lavers, 2015: How do atmospheric rivers form? Bull. Amer. Meteor. Soc., 96, 1243-1255, Crossref.

Davis, R. S., 2001: Flash flood forecast and detection methods. Severe Convective Storms, Meteor. Monogr., No. 50, Amer. Meteor. Soc., 481-526.

, 2004: The impact of tropical rainfall rates on flash flood detection. Preprints, 22nd Conf. on Severe Local Storms, Hyannis, MA, Amer. Meteor. Soc., 11B.5. [Available online at https://ams.confex.com/ams/pdfpapers/81521. pdf.]

Doswell, C. A., III, and E. N. Rasmussen, 1994: The effect of neglecting the virtual temperature correction on CAPE calculations. Wea. Forecasting, 9, 625-629, Crossref.

H. E. Brooks, and R. A. Maddox, 1996: Flash flood forecasting: An ingredients-based methodology. Wea. Forecasting, 11, 560-581, Crossref.

Farrell, R. J., and T. N. Carlson, 1989: Evidence for the role of the lid and underrunning in an outbreak of tornadic thunderstorms. Mon. Wea. Rev., 117, 857-871, Crossref.

Ferraro, R. R., 1997: Special sensor microwave imager derived global rainfall estimates for climatological applications. J. Geophys. Res., 102, 16 715-16 735, Crossref. , F. Weng, N. C. Grody, and L. Zhao, 2000: Precipitation characteristics over land from the NOAA-15 AMSU sensor. Geophys. Res. Lett., 27, 2669-2672, Crossref.

Forsythe, J. M., J. B. Dodson, P. T. Partain, S. Q. Kidder, and T. H. Vonder Haar, 2012: How total precipitable water vapor anomalies relate to cloud vertical structure. J. Hydrometeor., 13, 709-721, Crossref.
S. Q. Kidder, K. K. Fuell, A. LeRoy, G. J. Jedlovec, and A. S. Jones, 2015: A multisensor, blended, layered water vapor product for weather analysis and forecasting. J. Operational Meteor., 3 (5), 41-58, Crossref.

Funk, T. W., 1986: The use of water vapor imagery in the analysis of the November 1985 middle Atlantic states record flood event. Natl. Wea. Dig., 11 (4), 12-19. [Available online at nwafiles.nwas.org/digest/ papers/1986/Vol11-Issue4-Nov1986/Pg12-Funk.pdf.]

Gitro, C. M., M. S. Evans, and R. H. Grumm, 2014: Two major heavy rain/flood events in the mid-Atlantic: June 2006 and September 2011. J. Operational Meteor., 2 (13), 152-168, Crossref.

Graham, R., K. Barjenbruch, T. Lericos, and D. Berc, 2016: The September 2015 tragedies at Hildale/ Colorado City and Zion National Park: The intersection between hydrometeorology, topography, and human decision making. Preprints, 41st Annual Meeting, Norfolk, VA, Natl. Wea. Assoc. [Available online at www.nwas.org/meetings/nwas16/abstracts_html/ Communication/2016 2921 oral Graham abstract. html.]

Holmes, R. R., Jr., and D. M. Wagner, 2011: Flood of June 11, 2010, in the Upper Little Missouri River Watershed, Arkansas. U.S. Geological Survey Scientific Investigations Report 2011-5194, 42 pp. [Available online at pubs.er.usgs.gov/publication/sir20115194.]

Jurewicz, M. L., 2018: A comparison of two particularly intense lake-effect snowstorms in central New York (5-9 December 2010 and 20-21 November 2016): Assessing the importance of Atlantic inflow and laketo-lake connectivity. Preprints, 22nd Conf. on Satellite Meteorology and Oceanography, Austin, TX, Amer. Meteor. Soc., 7.2. [Available online at ams.confex.com/ ams/98Annual/meetingapp.cgi/Paper/330698.]

Keighton, S. J., P. Corrigan, and J. Sikora, 2016: A review of the 23 June 2016 West Virginia historic flash floods: Use of emerging observational technologies to monitor threats. Preprints, 28th Conf. on Severe Local Storms, Portland, OR, Amer. Meteor. Soc., 2. [Available online at ams.confex.com/ams/28SLS/webprogram/ Paper300972.html.]

Kidder, S. Q., and A. S. Jones, 2007: A blended satellite total precipitable water product for operational forecasting. $J$. Atmos. Oceanic Technol., 24, 74-81, Crossref.

Lavers, D. A., and G. Villarini, 2013: Atmospheric rivers and flooding over the central United States. J. Climate, 26, 7829-7836, Crossref.

LeRoy, A., K. K. Fuell, A. L. Molthan, G. J. Jedlovec, J. M. Forsythe, S. Q. Kidder, and A. S. Jones, 2016: The operational use and assessment of a layered precipitable water product for weather forecasting. J. Operational Meteor., 4 (2), 22-33, Crossref. 
Maddox, R. A., 1981: Satellite depiction of the life cycle of a mesoscale convective complex. Mon. Wea. Rev., 109, 1583-1586, Crossref.

, L. R. Hoxit, C. F. Chappell, and F. Caracena, 1978: Comparison of meteorological aspects of the Big Thompson and Rapid City flash floods. Mon. Wea. Rev., 106, 375-389, Crossref.

Mahoney, K. M., and Coauthors, 2016: Understanding the role of atmospheric rivers in heavy precipitation in the southeastern United States. Mon. Wea. Rev., 144, 1617-1632, Crossref.

McGuirk, J. P., and D. J. Ulsh, 1990: Evolution of tropical plumes in VAS water vapor imagery. Mon. Wea. Rev., 118, 1758-1766, Crossref.

Mogil, H. M., J. C. Monro, and H. S. Groper, 1978: NWS's flash flood warning and disaster preparedness programs. Bull. Amer. Meteor. Soc., 59, 690-699, Crossref.

Moore, B. J., P. J. Neiman, F. M. Ralph, and F. E. Barthold, 2012: Physical processes associated with heavy flooding rainfall in Nashville, Tennessee, and vicinity during 1-2 May 2010: The role of an atmospheric river and mesoscale convective systems. Mon. Wea. Rev., 140, 358-378, Crossref.

Moore, J. T., F. H. Glass, C. E. Graves, S. M. Rochette, and M. J. Singer, 2003: The environment of warm-season elevated thunderstorms associated with heavy rainfall over the central United States. Wea. Forecasting, 18, 861-878, Crossref.

Nayak, M. A., G. Villarini, and A. A. Bradley, 2016: Atmospheric rivers and rainfall during NASA's Iowa Flood Studies (IFloodS) campaign. J. Hydrometeorol. 17, 257-271, Crossref.

Neiman, P. J., F. M. Ralph, A. B. White, D. E. Kingsmill, and P. O. G. Persson, 2002: The statistical relationship between upslope flow and rainfall in California's coastal mountains: Observations during CALJET. Mon. Wea. Rev., 130, 1468-1492, Crossref.

Newell, R. E., N. E. Newell, Y. Zhu, and C. Scott, 1992: Tropospheric rivers? - A pilot study. Geophys. Res. Lett, 19, 2401-2404, Crossref.

NWS, 2011: Record floods of Greater Nashville: Including flooding in middle Tennessee and western Kentucky, May 1-4, 2010. NWS Service Assessment, 93 pp. [Available online at www.weather.gov/media/ publications/assessments/Tenn_Flooding.pdf.] ,2014: May 2013 Oklahoma tornadoes and flash flooding. NWS Service Assessment, 63 pp. [Available online at www.weather.gov/media/publications/ assessments/13oklahoma tornadoes.pdf.]

Ralph, F. M., P. J. Neiman, and G. A. Wick, 2004: Satellite and CALJET aircraft observations of atmospheric rivers over the eastern North Pacific Ocean during the winter of 1997/98. Mon. Wea. Rev., 132, 1721-1745, Crossref.
Rochette, S. M., J. T. Moore, and P. S. Market, 1999: The importance of parcel choice in elevated CAPE computations. Natl. Wea. Dig., 23 (4), 20-32. [Available online at nwafiles.nwas.org/digest/papers/1999/ Vol23No4/Pg20-Rochette.pdf.]

Rodgers, C. D., 2000: Inverse Methods for Atmospheric Sounding: Theory and Practice. World Scientific Publishing, 256 pp., Crossref.

Scofield, R. A., 1987: The NESDIS operational convective precipitation estimation technique. Mon. Wea. Rev., 115, 1773-1792, Crossref.

, G. Vicente, and M. Hodges, 2000: The use of water vapor for detecting environments that lead to convectively produced heavy precipitation and flash floods. NOAA Tech. Rep. NESDIS 99, 72 pp. [Available online at ntrs. nasa.gov/archive/nasa/casi.ntrs.nasa.gov/20000109862. pdf.]

Thiao, W., R. A. Scofield, and J. Robinson, 1995: The relationship between water vapor plumes and extreme rainfall events during the summer season. Natl. Wea. Dig., 19 (3), 26-50. [Available online at nwafiles.nwas. org/digest/papers/1995/Vol19-Issue3-Mar1995/Pg26Thiao.pdf.]

Vicente, G. A., R. A. Scofield, and W. P. Menzel, 1998: The operational GOES infrared rainfall estimation technique. Bull. Amer. Meteor. Soc., 79, 1883-1898, Crossref.

Weng, F., L. Zhao, R. R. Ferraro, G. Poe, X. Li, and N. C. Grody, 2003: Advanced microwave sounding unit cloud and precipitation algorithms. Radio Sci., 38 (4), 8068, Crossref.

Wimmers, A. J., and C. S. Velden, 2011: Seamless advective blending of total precipitable water retrievals from polarorbiting satellites. J. Appl. Meteor. Climatol., 50, 1024 1036, Crossref.

Zhu, Y., and R. E. Newell 1998: A proposed algorithm for moisture fluxes from atmospheric rivers. Mon. Wea. Rev., 126, 725-735, Crossref. 